\title{
Maternal mortality, marital status and bone mineral density in young women from the Coimbra identified skeletal collection
}

\author{
Francisco Curate ${ }^{1,2,3, *}$ and Ana Tavares ${ }^{4}$
}

\author{
1 Research Centre for Anthropology and Health, Department of Life Sciences, University of Coimbra, Portugal \\ 2 Laboratory of Forensic Anthropology, Department of Life Sciences, University of Coimbra, Coimbra, Portugal \\ 3 Interdisciplinary Center for Archaeology and Evolution of Human Behavior, University of Algarve, Faro, Portugal \\ 4 Department of Women and Children, Cascais Hospital - Dr. José de Almeida, Cascais, Portugal \\ * Corresponding author: fcurate@uc.pt; franciscocurate@gmail.com; ana.tavares.lopes@gmail.com
}

With 1 figure and 5 tables

\begin{abstract}
In contemporary populations, pregnancy and lactation are usually followed by transient bone loss. The observation of reduced bone mass in young females from archaeological sites has sometimes been interpreted as an outcome of reproductive stress. In order to evaluate the overall effect of reproductive dynamics on bone mass in a historical skeletal sample, bone mineral density (BMD) at the proximal femur was assessed by dual-energy X-ray absorptiometry in 78 young women (17-39 years) from the Coimbra Identified Skeletal Collection. BMD was compared within the skeletal sample ("maternal deaths" [ICD - 10: chapter XV] vs. "other causes of death", and "married/widowed women" vs. "single women"). Results revealed that mean BMD differences among groups are non-significant, suggesting that a strict reproductive interpretation of premature bone loss in young women from archaeological contexts is not sustained by empirical evidence. Bone mass in young women from archaeological sites should be interpreted as a complex trait stemming from the interplay between reproductive factors, genetics, nutrition, physical activity, and age at menarche.
\end{abstract}

Keywords: BMD; reproductive patterns; bone loss; reference skeletal collections

\section{Introduction}

Throughout pregnancy and breastfeeding, significant changes take place in the maternal calcium $(\mathrm{Ca})$ homeostasis and bone mineral metabolism to satisfy the Ca needs of the fetus and the neonate (Namgung \& Tsang 2003, Møller et al. 2012). Maternal Ca homeostasis is mostly affected during the last trimester of pregnancy and the ensuing lactation cycle, when calcium requirements surpass those observed in the early stages of pregnancy (Agarwal \& Stuart-Macadam 2003; Ulrich et al. 2003). The maternal skeleton struggles to adapt to the demand of $\mathrm{Ca}$ and other minerals, which are transferred through the placenta to mineralize the developing fetal skeleton. Likewise, the growing requirements of calcium during breastfeeding also appeal for an adjustment of the bone mineral homeostasis in the lactating woman (Agarwal 2008).

Pregnancy typically implicates a high bone turnover, with resorption anteceding formation. Bone remodeling uncouples during the first and second trimesters, with a peak in bone resorption in the last trimester (Ulrich et al. 2003). As such, bone mass can decrease during pregnancy, espe- cially at sites rich in trabecular bone, such as the trochanter or the lumbar vertebrae (Allali et al. 2007; Ulrich et al. 2003). Notwithstanding, hormonal regulatory mechanisms and metabolical adaptations in the maternal body oppose to bone loss during pregnancy by retaining the circulatory $\mathrm{Ca}$ in surplus, increasing intestinal absorption, and decreasing renal excretion of calcium (Namgung \& Tsang 2003; Ritchie et al. 1998). Moreover, bone mass can escalate due to higher estrogen levels in late pregnancy and the increased bone loading associated with weight gain during gestation (CureCure et al. 2002). Other factors, like physical activity, body mass and smoking habits, can influence bone mass during pregnancy, reducing or increasing it (Karlsson et al. 2005; To \& Wong 2012; Jang et al. 2016; Wei et al. 2017).

The effect of gestation upon the maternal skeleton is still not fully understood, with different epidemiological studies showing conflicting results about the overall gain or loss of bone mass during pregnancy. Nevertheless, most of the studies have found that bone mineral density (BMD) decreases in response to the transfer of calcium to the skeleton of the developing fetus (Ritchie et al. 1998; Karlsson et al. 2005; Kraemer et al. 2012; Møller et al. 2012).BMDdecline during 
pregnancy corresponds to a theoretical value of $3 \%$; assuming that the fetal $\mathrm{Ca}$ requirements of about $30 \mathrm{~g}$ are entirely met by the mother but reported reduction can reach $9 \%$ (Ritchie et al. 1998), depending of the skeletal site. Other studies have reported unchanged or even increased values of bone mineral density (Cross et al. 1995; Holmberg-Marttila et al. 1999; Cure-Cure et al. 2002; Wei et al. 2017). Interestingly, some studies described a BMD decrease at some skeletal sites and an increase at others. For example, Ulrich et al. (2003) observed that BMD significantly decreased at the lumbar spine and the trochanter, while there was a significant BMD increase at the proximal $1 / 3$ of the forearm. At other anatomical regions, like the total hip, the femoral neck and the ultradistal forearm, BMD did not change significantly.

Data from epidemiological and animal studies considering the cumulative influence of reproductive events (such as parity) on bone mass and/or fractures rate are inconsistent (Cavkaytar et al. 2015) - a feature also observed in one bioarchaeological study (Mays 2000). While some studies reported an increase in BMD connected with the number of live births (Henderson et al. 2000; Cure-Cure et al. 2002; Streeten et al. 2005), others conveyed a null or negative association between parity and BMD (Kojima et al. 2002; Allali et al. 2007; Cavkaytar et al. 2015; Crandall et al. 2017). The duration of the fertility period seems to be positively correlated with BMD (Sioka et al. 2010; Cavkaytar et al. 2015). Finally, and although $\mathrm{Ca}$ demands of pregnancy are high, osteoporosis associated with pregnancy is a rare clinical condition (Krishnakumar et al. 2016).

Most studies have reported a decrease in BMD during breastfeeding, but the relative influence of lactation on BMD variation at different skeletal sites is still an undecided matter (Kolthoff et al. 1998; Laskey \& Prentice 1999; Kojima et al. 2002; Møller et al. 2012; Jang et al. 2016). BMD usually decreased $4-5 \%$ at the lumbar spine (Laskey \& Prentice 1999; Møller et al. 2012) or increased (Cooke-Hubley et al. 2017), whereas at the hip BMD decreased between 2 and 4\% (Kolthoff et al. 1998; Møller et al. 2012). The duration and intensity of breastfeeding seem to influence bone mineral density, with greater intensity of breastfeeding associated with a significant attenuation of bone loss (Pearce 2006). During breastfeeding, the maternal skeleton loses $\mathrm{Ca}$ through milk and the lactation-associated amenorrhea also contributes to bone loss (Kojima et al. 2002). The neonate typically requires circa $200 \mathrm{mg}$ calcium per day from milk during the first 6 months (Kovacs 2016). Also, biochemical markers of bone formation and resorption indicate that there is an increase of bone turnover at least during the first six months of lactation (Prentice 2000). Bone loss is characteristically restored within 6-12 months after the interruption of lactation (Ferrari et al. 2012).

Bone health associated with reproductive behavior has been studied (albeit indirectly) in different archaeological contexts, and reduced bone mass in young females has sometimes been interpreted as the consequence of transient reproductive stress (Agarwal 2001; Agarwal \& StuartMacadam 2003; Agarwal 2008; Brickley \& Ives 2008). Dewey et al. (1969), in a seminal analysis carried out in three skeletal samples from Sudanese Nubia, observed a significant precocious cortical thinning in females, imputed to a combination of poor calcium intake and prolonged breastfeeding. Armelagos et al. (1972), studying part of the original sample from Dewey et al. (1969), also suggested that the precocious cortical bone loss observed in females reflected the physiological stress associated with extended breastfeeding and inadequate calcium consumption. Subsequent studies employing different techniques to assess bone mass and focused in only one of the samples from Sudanese Nubia (X-Group A.D. 350-550) maintained the emphasis on the reproductive factors affecting bone mass (Martin \& Armelagos 1979; White \& Armelagos 1997).

In contrast, Ericksen (1976) expressed reluctance to ascribe any differences in bone mass observed in three Native American populations to the effects of pregnancy and lactation. Vogel et al. (1990) suggested that parity might have enhanced trabecular connectivity in females from European historical samples. A decade later, Poulsen et al. (2001) considered that BMD age-related decline in a group of Danish medieval women and, sequentially, BMD relative increase in older age could be justified by features connected to childbearing. The authors suggested that the observed higher mortality (no statistics were given) among the younger women was associated with a low BMD. The leading reasons for the high mortality would encompass the increased physiological demands associated with pregnancy and lactation, so that only the strongest women survived to older ages. It was also suggested that bone loss observed in the young women from English and Norwegian medieval samples could be related to the fact that these individuals died during their reproductive age and thus were possibly pregnant or breastfeeding at the time of death (Turner-Walker et al. 2001; Agarwal \& Stuart-Macadam 2003; Agarwal et al. 2004; Mays et al. 2006). Agarwal et al. (2004) summarize this interpretation implying that the reduced bone mass observed in young women from archaeological samples is plausible. A radiogrammetric study in the Coimbra identified Skeletal Collection found no significant differences in the metacarpal cortical parameters between young women who died from pregnancy complications and from other causes (Curate et al. 2012).

Epidemiological and anthropological studies address the relevance of reproductive dynamics to bone health, both during childbearing and childrearing, and later in life. The main purpose of this study was to evaluate the overall influence of reproductive factors (pregnancy and marital status) on bone mass in an identified skeletal sample of young adult women from Coimbra (Portugal). Therefore, BMD in young women who died of conditions related or aggravated by the pregnancy, childbirth, or the puerperium, and those who died from other causes was compared (age range 17-39 years). 
Since it is not possible to know for sure if these latter women were not pregnant or lactating when they died, BMD values of married/widowed young females were equated with those of single young women - admitting that the reproductive dynamics (hence, the hormonal milieu) in each group were distinctive. The effect of reproductive factors on bone mass in archaeological contexts is also discussed.

\section{Material and methods}

Eusébio Tamagnini compiled the Coimbra Identified Skeletal Collection, curated at the Anthropological Museum in the University of Coimbra, between 1915 and 1942. The collection includes 505 skeletons with documented sex, age at death, cause of death, occupation, among other biographical information; the majority was exhumed from the Coimbra municipal cemetery, Cemitério da Conchada, where individuals were buried for at least five years. All the collected individuals, mostly Portuguese nationals with low socioeconomic status and engaged in non-qualified manual labor, were born between 1822 and 1921, and died between 1904 and 1936 (Cunha \& Wasterlain 2007).

All women between 17 and 39 years in the CISC were co-opted into the study sample $(\mathrm{N}=86)$. The fertile period of a woman is usually considered from 15 to 45 years, but historical records suggest that, for the most part, last maternity occurred circa 40 years or before (Head-König et al. 2001). Individuals lacking crucial information (e.g., cause of death), displaying gross diagenetic and/or pathological changes in both femurs, or of non-Portuguese ancestry, were excluded (three exclusions due to taphonomic damage, two to ancestry, one to pathological changes in both femora, one to unspecified cause of death and one to absence of the femora). As such, the definitive study sample included 78 young females, mostly from Central Portugal (districts of Coimbra, Guarda, Leiria, Viseu, Aveiro, Castelo Branco and Santarém; $92.3 \%$ [72/78]) and belonging to the underprivileged socioeconomic classes. The overwhelming majority were housewives or employed as domestic servants. They were all born between 1873 and 1917, and died between 1910 and 1936. There were 35 single women (44.9\%) and 43 married/widowed women (55.1\%, with only three widows). Mean age at death was significantly different between groups of marital status (Single: 25.4 years; $\mathrm{SD}=6.8 ; 95 \%$ CI $23.1-27.8$ / Married or widowed: 29.7 years; $\mathrm{SD}=6.3 ; 95 \%$ CI 27.8 31.6; Student's t: -2.853 ; df $=76 ; p=0.006$ ).

Maternal Mortality is "defined as a death of a woman while pregnant or within 42 days of termination of pregnancy, irrespective of the duration and site of pregnancy, from any cause related or aggravated by the pregnancy or its management, but not from accidental or incidental injuries" (World Health Organization 1994). Seven women from the study sample died unequivocally of conditions related to or aggravated by the pregnancy, childbirth or the puerperium
Table 1. Causes of death (ICD-10) in the CISC study sample.

\begin{tabular}{|c|c|}
\hline N (\%) & $\begin{array}{l}\text { Cause of death } \\
\text { (International Classification of Diseases 10) }\end{array}$ \\
\hline 31 (39.7) & $\begin{array}{l}\text { I (A00-B99): } \\
\text { Certain infectious and parasitic diseases }\end{array}$ \\
\hline $6(7.7)$ & $\begin{array}{l}\text { II (C0-D48): } \\
\text { Neoplasms }\end{array}$ \\
\hline $2(2.6)$ & $\begin{array}{l}\text { III (D50-D89): } \\
\text { Diseases of the blood and blood-forming organs and } \\
\text { certain disorders involving the immune mechanism }\end{array}$ \\
\hline $1(1.3)$ & $\begin{array}{l}\text { VI (G00-G99): } \\
\text { Diseases of the nervous system }\end{array}$ \\
\hline $6(7.7)$ & $\begin{array}{l}\text { IX (I00-I99): } \\
\text { Diseases of the circulatory system }\end{array}$ \\
\hline $6(7.7)$ & $\begin{array}{l}\text { X (J00-J99): } \\
\text { Diseases of the respiratory system }\end{array}$ \\
\hline $11(14.1)$ & $\begin{array}{l}\mathrm{XI}(\mathrm{K} 00-\mathrm{K} 93) \text { : } \\
\text { Diseases of the digestive system }\end{array}$ \\
\hline $3(3.8)$ & $\begin{array}{l}\text { XIV (N00-N99): } \\
\text { Diseases of the genitourinary system }\end{array}$ \\
\hline $7(9.0)$ & $\begin{array}{l}\text { XV (O00-O99): } \\
\text { Pregnancy, childbirth and the puerperium }\end{array}$ \\
\hline $2(2.6)$ & $\begin{array}{l}\text { XVIII (R00-R99): } \\
\text { Symptoms, signs and abnormal clinical and } \\
\text { laboratory findings, not elsewhere classified }\end{array}$ \\
\hline $1(1.3)$ & $\begin{array}{l}\text { XIX (S00-T98): } \\
\text { Injury, poisoning and certain other consequences of } \\
\text { external causes }\end{array}$ \\
\hline $2(2.6)$ & $\begin{array}{l}\text { XX (V01-Y98): } \\
\text { External causes of morbidity and mortality }\end{array}$ \\
\hline
\end{tabular}

(ICD-10: chapter $\mathrm{XV})$ : peritonitis after an abortion $(\mathrm{N}=1)$, dystocic labor, with dead fetus $(\mathrm{N}=1)$, placenta praevia $(\mathrm{N}=1)$, uterine rupture, with injured fetus $(\mathrm{N}=1)$, and puerperal infections $(\mathrm{N}=3)$. The remaining women in the sample died of other causes $(\mathrm{N}=71$; Table 1$)$. Mean age at death of women who died of pregnancy complications was 28.0 years $(\mathrm{SD}=7.0 ; 95 \% \mathrm{CI} 21.5-29.3)$, while in the "other causes of death" group was 27.8 years $(\mathrm{SD}=6.9 ; 95 \%$ CI 26.1-29.3). The difference is not significant (Student's t: -0.093 ; $\mathrm{df}=$ $76 ; p=0.926)$.

Bone mineral density (BMD, $\mathrm{g} / \mathrm{cm}^{2}$ ) was evaluated in four regions of interest (ROI) of the proximal femur ("neck", "trochanter", "intertrochanteric region", and "total hip"; Fig. 1) through dual-energy X-ray absorptiometry (DXA). BMD at the Ward's area was not included in the study because measurement imprecision in this region is substantial (Bonnick 2010). The left femur from each sampled young woman was scanned with a Hologic QDR-4500A densitometer (Hologic, Inc., Bedford, MA) at the Serviço de Medicina Nuclear, Centro Hospitalar e Universitário de Coimbra, Portugal. When absent, or altered by diagenetic changes or pathological conditions, the left femur was 


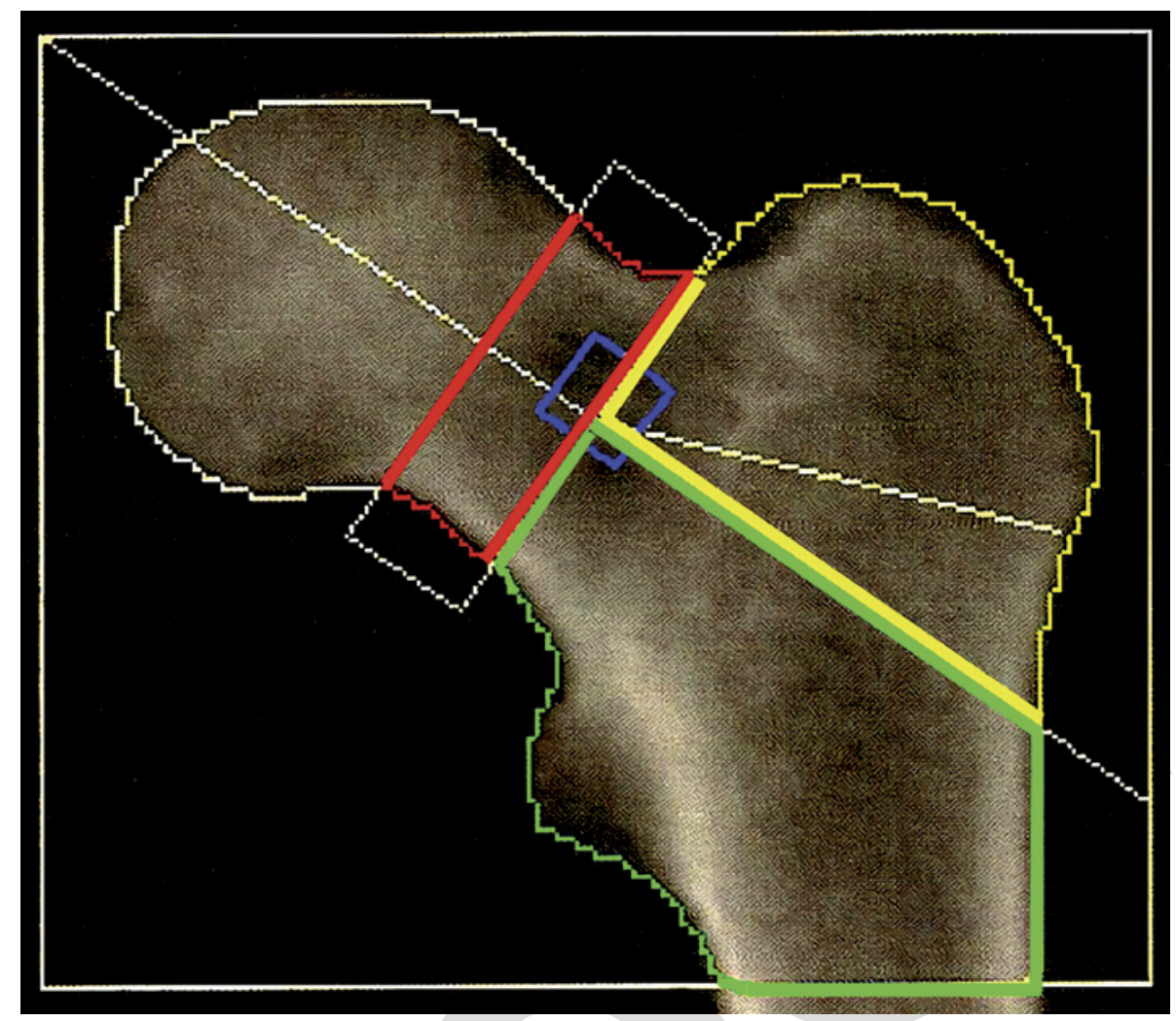

Fig. 1. Densitometric image of a proximal femur; red line: femoral neck, yellow line: trochanteric region, green line: intertrochanteric region, blue line: Ward's area; the total hip is the sum of three individual regions of interest: femoral neck, trochanteric region, and intertrochanteric region.

replaced by its right counterpart (just one case). Direct and indirect analyses - macroscopical analysis, absence of soil erosion (i.e., macroscopical destruction of endocortical or trabecular bone caused by soil) on plain radiographs $(n=28)$, microradiography (Bergot et al. 2009), and epidemiologically expected patterns of bone loss (Curate et al. 2013) - suggest that the sample from the CISC is in appropriate state of preservation. Usually, BMD values are highly correlated in both femora (Bonnick 2010). Each femur was placed anteroposteriorly, with the shaft parallel to the central axis of the scanner, in a low-density paper container, directly above $10 \mathrm{~cm}$ of dry rice (which acted as a soft-tissue substitute). To increase the reproducibility the femur was internally rotated circa 35 degrees (Curate 2014a). Twenty-five femora were scanned in two different days to check repeatability of the DXA measurements. The magnitude of the measurement error at the total hip and neck was assessed through the relative technical error of measurement (rTEM), following Ulijaszek \& Kerr (1999):

$T E M=\sqrt{\frac{\sum \mathrm{D}^{2}}{2 \mathrm{~N}}}$ and

$r T E M=\frac{\mathrm{TEM}}{\mathrm{VMV}} \times 100$,

where TEM is the technical error of measurement, D is the difference between the first and second observation, $\mathrm{N}$ is the number of femora measured in two different instances, and VMV is the variable mean value. Measurements with a rTEM value inferior to $5 \%$ were considered precise.

Statistical analysis was performed with IBM $^{\circledR}$ SPSS $^{\circledR}$ (version 20.0.0). Descriptive statistics, including group means, standard deviation (SD) and 95\% confidence intervals $(95 \% \mathrm{CI})$ for the mean were estimated for each variable. The assumption of normality was evaluated through the skewness and kurtosis of the distributions (Kline 2010) and normal Q-Q plots. Homoscedasticity was assessed with the Levene's test. Student's t-test for independent samples was used to evaluate the null hypothesis that the means of two groups were equal. Analysis of variance (ANOVA) was used to compare means in more than two groups. Linear Pearson 
correlation was employed to associate bone mineral density with recorded age at death and long bones length.

A measure of size effect was computed using the standardized mean difference for two groups ( $d$; Cohen 1988), as follows:

Cohen's $d=\frac{m 2-m 1}{s d \text { pooled }}$,

where $m 1$ and $m 2$ are the means of two groups and $s d_{\text {pooled }}$ is the pooled standard deviation. Eta squared $\left(\eta^{2}\right.$, the proportion of the total variability explained by each factor) was computed as a measure of size effect for ANOVA effects (Levine \& Hullett 2002).

\section{Results}

\section{Repeatability}

The relative technical error of measurement for BMD measurements is $0.6 \%$ at the total hip and $2.3 \%$ at the neck.

\section{BMD and reproductive factors}

Bone mineral density is not linearly correlated with age at death in this sample of young women (Pearson's $r_{\text {neck*age: }}$ $-0.112 ; p=0.327$ / Pearson's $\mathrm{r}_{\text {trochanter*age: }}-0.018 ; p=$

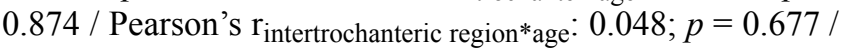
Pearson's $\left.\mathrm{r}_{\text {total hip*age: }}-0.025 ; p=0.827\right)$. There is a slight decline of BMD in all the examined regions of interest of the proximal femur from the 17-19 years age class to the 20-29 age category, and a small increase from this group to the oldest (30-39 years; Table 2), but the differences are not significant (Anova $\mathrm{F}_{\text {neck }}: 1.008 ; \mathrm{df}=2 ; p=0.370$; $\eta^{2}=0.026 /$ Anova $\mathrm{F}_{\text {trochanter }}: 1.019 ; \mathrm{df}=2 ; p=0.366$; $\eta^{2}=0.027$ / Anova $\mathrm{F}_{\text {intertrochanteric }}: 0.630 ; \mathrm{df}=2 ; p=0.535$ $\eta^{2}=0.017 /$ Anova $F_{\text {total hip }}: 0.008 ; \mathrm{df}=2 ; p=0.601$; $\left.\eta^{2}=0.013\right)$.

BMD results for the "maternal deaths" and "other causes of death" groups are shown in Table 3. Although mean BMD is higher in the "ICD-10: chapter XV" group, the tests failed to reject the null hypothesis. Cohen's $d$ (a measure of size effect) for each ROI is depicted in Table 4. Also, there are no differences in BMD values between any of the "ICD-10 causes of death" groups (Anova $F_{\text {neck: }}$ 1.032;

Table 2. Age at death categories and BMD values $\left(\mathrm{g} \mathrm{cm}^{-2}\right)$ in the proximal femur. Data provided with standard deviation (SD) and 95\% confidence intervals $(95 \% \mathrm{Cl})$.

\begin{tabular}{|l|c|c|c|c|c|}
\hline Region of interest & Age category & Mean & SD & 95\% CI & N \\
\hline \multirow{3}{*}{ BMD $_{\text {neck }}$} & $17-19$ & 0.851 & 0.17 & $0.736-0.967$ & 11 \\
\cline { 2 - 6 } & $20-29$ & 0.790 & 0.10 & $0.754-0.827$ & 34 \\
\cline { 2 - 6 } & $30-39$ & 0.802 & 0.13 & $0.750-0.843$ & 33 \\
\cline { 2 - 6 } & $17-19$ & 0.725 & 0.13 & $0.633-0.817$ & 11 \\
\cline { 2 - 6 } & $20-29$ & 0.675 & 0.09 & $0642-0.708$ & 34 \\
\hline BMD $_{\text {intertrochanteric }}$ & $30-39$ & 0.701 & 0.11 & $0.660-0.742$ & 33 \\
\cline { 2 - 6 } & $17-19$ & 1.072 & 0.20 & $0.939-1.205$ & 11 \\
\cline { 2 - 6 } & $20-29$ & 1.030 & 0.11 & $0.991-1.070$ & 34 \\
\hline BMD $_{\text {total hip }}$ & $30-39$ & 1.065 & 0.14 & $1.012-1.117$ & 33 \\
\cline { 2 - 6 } & $17-19$ & 0.928 & 0.17 & $0.815-1.042$ & 34 \\
\hline
\end{tabular}

Table 3. Maternal deaths BMD values $\left(\mathrm{g} \mathrm{cm}^{-2}\right)$ in the proximal femur. Data provided with standard deviation (SD) and $95 \%$ confidence intervals $(95 \% \mathrm{Cl})$.

\begin{tabular}{|l|c|c|c|c|c|c|c|c|c|c|}
\hline & \multicolumn{4}{|c|}{ Maternal deaths (ICD-10: chapter XV) } & \multicolumn{4}{c|}{ Other causes of death } & \multicolumn{2}{c|}{ Student's t test } \\
\cline { 2 - 13 } & Mean & SD & $\mathbf{9 5 \%}$ CI & N & Mean & SD & 95\% CI & N & \multicolumn{1}{c|}{$\boldsymbol{s}$} & sig. \\
\hline $\mathrm{BMD}_{\text {neck }}$ & 0.865 & 0.13 & $0.740-0.990$ & 7 & 0.796 & 0.13 & $0.766-0.825$ & 71 & -1.396 & 0.167 \\
\hline $\mathrm{BMD}_{\text {trochanter }}$ & 0.763 & 0.12 & $0.649-0.877$ & 7 & 0.686 & 0.11 & $0.661-0.711$ & 71 & -1.792 & 0.077 \\
\hline $\mathrm{BMD}_{\text {intertrochanteric }}$ & 1.143 & 0.20 & $0.962-1.325$ & 7 & 1.041 & 0.13 & $1.010-1.073$ & 71 & -1.837 & 0.070 \\
\hline $\mathrm{BMD}_{\text {total hip }}$ & 0.937 & 0.17 & $0.778-1.097$ & 7 & 0.894 & 0.12 & $0.865-0.922$ & 71 & -0.874 & 0.385 \\
\hline
\end{tabular}

$t$ : value of the t test; sig.: significance. 
Table 4. Size effect measure ( $d$ statistics) in group comparisons. Data provided with $95 \%$ confidence intervals $(95 \% \mathrm{Cl})$ and percent overlap (\% overlap).

\begin{tabular}{|c|c|c|c|}
\hline Group comparisons & Cohen's $d$ & $95 \% \mathrm{CI}$ & \% overlap \\
\hline Maternal Deaths vs. Other Causes $\left(\mathrm{BMD}_{\text {neck }}\right)$ & -0.5530 & $-1.3343-0.2283$ & $\sim 66.6$ \\
\hline Maternal Deaths vs. Other Causes $\left(\mathrm{BMD}_{\text {trochanter }}\right)$ & -0.7099 & $-1.4943-0.0745$ & $\sim 57.0$ \\
\hline Maternal Deaths vs. Other Causes (BMD $\left.{ }_{\text {trochanteric region }}\right)$ & -0.7277 & $-1.5126-0.0571$ & $\sim 57.0$ \\
\hline Maternal Deaths vs. Other Causes (BMD total hip $)$ & -0.3462 & $-1.1246-0.4321$ & $\sim 78.7$ \\
\hline Single $v s$. Married/Widowed $\left(\mathrm{BMD}_{\text {neck }}\right)$ & 0.0314 & $-0.4148-0.4776$ & $\sim 100$ \\
\hline Single vs. Married/Widowed $\left(\mathrm{BMD}_{\text {trochanter }}\right)$ & 0.1746 & $-0.2724-0.6217$ & $\sim 85.3$ \\
\hline Single vs. Married/Widowed $\left(\mathrm{BMD}_{\text {trochanteric region }}\right)$ & -0.0305 & $-0.4767-0.4157$ & $\sim 100$ \\
\hline Single $v s$. Married/Widowed (BMD total hip $)$ & 0.0936 & $-0.3529-0.5400$ & $\sim 92.3$ \\
\hline
\end{tabular}

Table 5. Marital status in young women from the CISC and BMD values $\left(\mathrm{g} \mathrm{cm}^{-2}\right)$ in the proximal femur. Data provided with standard deviation (SD) and 95\% confidence intervals (95\% Cl).

\begin{tabular}{|l|c|c|c|c|c|c|c|c|c|c|}
\hline & \multicolumn{4}{|c|}{ Married/Widowed } & \multicolumn{4}{c|}{ Single } & \multicolumn{2}{c|}{ Student's t test } \\
\cline { 2 - 33 } & Mean & SD & $\mathbf{9 5 \%}$ CI & N & Mean & SD & $\mathbf{9 5 \%}$ CI & N & \multicolumn{1}{c|}{ sig. } \\
\hline $\mathrm{BMD}_{\text {neck }}$ & 0.800 & 0.14 & $0.756-0.844$ & 43 & 0.804 & 0.10 & $0.768-0.840$ & 35 & 0.138 & 0.890 \\
\hline $\mathrm{BMD}_{\text {trochanter }}$ & 0.684 & 0.12 & $0.647-0.722$ & 43 & 0.704 & 0.10 & $0.671-0.736$ & 35 & 0.767 & 0.446 \\
\hline $\mathrm{BMD}_{\text {intertrochanteric }}$ & 1.053 & 0.16 & $1.004-1.101$ & 43 & 1.048 & 0.12 & $1.007-1.090$ & 35 & -0.134 & 0.894 \\
\hline $\mathrm{BMD}_{\text {total hip }}$ & 0.892 & 0.14 & $0.849-0.936$ & 43 & 0.904 & 0.10 & $0.869-0.940$ & 35 & 0.411 & 0.683 \\
\hline
\end{tabular}

$t$ : value of the t test; sig.: significance.

$\mathrm{df}=11 ; p=0.429 ; \eta^{2}=0.146 /$ Anova $\mathrm{F}_{\text {trochanter }}: 0.865$ $\mathrm{df}=11 ; p=0.578 ; \eta^{2}=0.126 /$ Anova $\mathrm{F}_{\text {intertrochanteric }}$ : 0.731 ; $\mathrm{df}=11 ; p=0.705 \eta^{2}=0.109$ / Anova $\mathrm{F}_{\text {total hip }}: 0.543 ; \mathrm{df}=$ $\left.11 ; p=0.867 ; \eta^{2}=0.083\right)$.

Married/widowed young women tend to exhibit a lower mean bone mineral density in the analyzed ROI (except for $\mathrm{BMD}$ at the intertrochanteric region) but the differences are not statistically significant, implying that marital status did not significantly influenced BMD. Cohen's effect size values suggest low practical significance (Table 4). Statistics are summarized in Table 5.

\section{Discussion}

\section{Repeatability}

The relative technical error of measurement expresses observation error as a percentage corresponding to the total average of the measured variables. rTEM values suggest that the variation in measurements of BMD at the neck of the femur and the total hip is very low.

\section{BMD and reproductive factors}

Peak bone mass is achieved during early adult years and bone mineral density is usually preserved until the late thirties (Nguyen et al. 2009). As such, and although bone loss is a universal result of ageing occurring in both sexes, independently of gonadal hormone levels (Curate 2014a; Lems
\& Raterman 2017), an age-related constancy in BMD values within the young females' sample was expected.

Women who died while being pregnant, or shortly after, did not have lower BMD values. Pregnancy is a high turnover physiological event, peaking in third trimester (Ulrich et al. 2003). Therefore, bone mass can decline during gestation (Allali et al. 2007). However, results from epidemiological studies are contradictory. Hormonal and metabolical adaptations in the maternal body oppose bone loss during gestation (Namgung \& Tsang 2003) and lifestyle factors, such as physical activity, seem to influence bone mass during this period (To \& Wong 2012). Pregnancy also involves weight gain, which increases mechanical loading and calcium intestinal absorption (Karlsson et al. 2005; Streeten et al. 2005; Jang et al. 2016). However, it is important to note that high fertility is sometimes associated with poor nutritional status (Haloi \& Limbu 2013).

Childbirth can even be associated with a "gestational bone mass peak" (Cure-Cure et al. 2002), with an increase in the bone mineral density and total bone and calcium content in all skeletal areas after each parturition. All maternal deaths in the CISC sample (except the abortion, which probably occurred during the third trimester of pregnancy) took place during birth or shortly after. As such, BMD in the "maternal deaths" must be interpreted considering that pregnancy effects upon the maternal skeleton are doubtfully understood, with a large array of factors affecting bone mass not only during gestation, but also during early adulthood 
(Karlsson et al. 2005; Nguyen et al. 2009; Plochocki 2009). As previously stated, another paleopathological study in the CISC, with a smaller sample and using second metacarpal radiogrammetry to evaluate cortical bone mass, found no significant differences in the cortical index, total diaphysis width and medullary width between the "maternal deaths" and "other causes of death" groups (Curate et al. 2012).

Data from the Portuguese national statistical surveys during the first half of the $20^{\text {th }}$ century show that most of the births occurred within marriage. Although illegitimacy was not negligible, the total fertility rate among married women was much higher when compared to single women (Nazareth 1978). In 1930, the mean number of offspring per woman was 3.9, ranging from 3.3 in Coimbra and 4.4 in Guarda (Morais 1983) - almost half of the parous women had three or more children, with $8.2 \%$ having nine or more (Barata 1985). Also, breastfeeding periods were long (Alves \& Almeida 1992). It is reasonable to believe that the reproductive dynamics amongst married/widowed young women and single young women at the CISC sample were rather different, with the former being more prone to transient reproductive stress, i.e., multiple pregnancies and extended periods of lactation. Still, there is no significant difference in the proximal femur BMD between the groups of marital status. During gestation and breastfeeding there is a suite of behavioral and hormonal changes that have the potential to influence BMD: alcohol consumption, level of physical activity, nutrition, body weight, estrogen levels, soft tissue composition, intensity, and duration of lactation (Karlsson et al. 2005; Pearce 2006; Piperata 2009). While some of these factors will reduce BMD, some will increase it - making difficult to predict BMD development during pregnancy and lactation (Karlsson et al. 2005).

The results are not consistent with strict interpretations suggesting that low bone mass in young women from archaeological sites is due to reproductive stress - but this study has some limitations. First, the number of maternal deaths in the CISC sample is small, which reduces the power of statistical tests to detect BMD differences (if any) between individuals that died while pregnant, or shortly after, and individuals killed by other causes (although the use of an effect size with a confidence interval, like Cohen's $d$, highlights the practical significance, rather than the sample sizes). Second, it is impossible to know baseline BMD in the "maternal deaths" group (i.e.,BMD just before pregnancy) making impossible to know for sure if BMD decreased, increased, or has remained stable during pregnancy. Finally, the reconstruction of the entire reproductive history (e.g., number of pregnancies, lactation periods, etc.) of these women is unfeasible, and while we can presume the major tendencies in the past reproductive dynamics, we must assume the limitations inherent to any generalization. Examining the few existing reference skeletal collections or the maternal deaths documented in archaeological samples (e.g.,Willis \& Oxenham 2013) can - at least hypotheti- cally - mitigate the first problem, but the others will persist unsolved.

The difficulties pertaining the study of BMD and reproductive factors in archaeological contexts are even more challenging. The observation of female precocious bone loss in paleopathological studies (e.g., Ekenman et al. 1995; Holck 2007; Mays et al. 2006; Agarwal \& Grynpas 2009) is sometimes interpreted in a context of reproductive stress (e.g., Armelagos et al. 1972; Martin et al. 1984; Martin et al. 1985; Agarwal 2001; Poulsen et al. 2001; Turner-Walker et al. 2001; Agarwal et al. 2004). Agarwal et al. (2004: 42) have suggested that early bone loss observed in young women from archaeological samples is expected, as "we may simply be observing skeletons of premenopausal women of reproductive age who were pregnant or breast-feeding at time of death". Although this is theoretically acceptable, it is not exempt of empirical problems.

First, early bone loss in women from archaeological samples is not a universal finding. For example, Lees et al. (1998: 675) did not find any evidence of premenopausal bone loss in the Spitalfields collection, even recognizing that "modern-day women had lost femoral neck bone density premenopausally significantly faster than did the Spitalfields women". Kneissel et al. (1997) did not detect bone loss in medieval Nubian women before 40 years, and Cho \& Stout (2003) suggest that ancient Romans at Isola Sacra, of both sexes, attained a greater peak bone mass than modern counterparts. A microradiographic evaluation of the degree of cortical bone mineralization in the femoral shaft in a sample from the CISC did not observe premature undermineralization of bone in females - before 50 years of age, mineralization was even higher in females than in males from the same age category (Bergot et al. 2009). Likewise, female early bone loss in high fertility modern samples is not more pronounced than in low fertility samples (e.g., El Maghraoui et al. 2006; Madimenos et al. 2011; Madimenos et al. 2012), and BMD can be maintained in the context of a fluctuating hormone environment connected to multiple pregnancies and prolonged lactation periods without recovery intervals (Henderson et al. 2000).

Furthermore, any attempt to ascertain the detrimental impacts of pregnancy and lactation on maternal bone health in the past (Brickley \& Ives 2008) is hampered by age at death estimation. Biological aging exhibits great phenotypic variation, and the estimation of age at death in adult skeletal remains usually yields poor to mediocre assessments of both biological and chronological age (Cunha et al. 2009). As Mays et al. (1998) rightly point out, it is very difficult to interpret bone loss in an age class such as the $50+$ years group. Of course, there is also an indiscriminate merging of individuals of disparate ages in the 30-49 years age class. Hence, an observed "significant statistical difference" between these two age categories does not imply a biological causation (i.e., a "reproductive" or "hormonal" causation). 
Reproductive patterns were undoubtelly different between historical and modern Westernized women (Sperling \& Beyene 1997; Agarwal \& Stuart-Macadam 2003; Luna et al. 2014), which can explain poor bone health and trabecular bone architecture in young historical females (Agarwal 2001; Agarwal \& Stuart-Macadam 2003). However, there is an enormous variation in reproductive dynamics among and within human populations, with very few univariant aspects in women's reproduction. Human reproductive histories in the past were as diverse as now, with geographical, ecological, cultural, or individual adjustments (Sperling \& Beyene 1997; Chamberlain 2006). Human reproductive experiences are directly shaped by individual behavior, with parameters such as celibacy, age at first marriage or conscious birth spacing influencing population fertility (Chamberlain 2006).

BMD is a complex phenotypic trait, whose expression is influenced by several environmental, hormonal, and genetic factors (Zhang et al. 2009; Curate 2014b). In historical populations, bone mass in young females has been related with pregnancy and lactation stress (e.g., Poulsen et al. 2001; Agarwal et al. 2004; Mays 2010), nutrition (e.g., Pfeiffer \& Lazenby 1994; Turner-Walker et al. 2001) or physical activity (e.g., Mulhern \& Van Gerven 1997; Peck \& Stout 2007), but associations with age at menarche, genetics or ancestry are not common, in spite of their well known impact on bone mass (Zhang et al. 2009; Madimenos et al. 2012; Henderson $\&$ Padez 2017). A multi-method evaluation of bone health in past populations is also warranted (Beauchesne \& Agarwal 2017).

\section{Conclusions}

BMD at the proximal femur in a group of young females from the Coimbra Collection was not influenced by marital status or cause of death; and the observed results do not support a straightforward association between reproductive stress and premature bone loss in skeletal samples. Although reproductive factors probably influenced bone mass in young women found in archaeological contexts, a strict "reproductive explanation" for early bone loss in historical females is unwarranted. Bone mass in historical young adult women from archaeological contexts has many correlates, stemming from a complex interplay of risk factors and must be addressed in a biocultural framework (Agarwal 2008; Brickley \& Ives 2008), exploring local interpretations and multilevel models of causation.

\section{References}

Agarwal, S.C. (2001): The effects of pregnancy and lactation on the maternal skeleton: a historical perspective. - Am. J. Phys. Anthropol. 114: 30.
Agarwal, S.C. (2008): Light and broken bones: examining and interpreting bone loss and osteoporosis in past populations. - In: Katzenberg, A. \& Saunders, S. (eds): Biological Anthropology of the human skeleton. - John Wiley \& Sons, Hoboken, NJ, pp. 387-410.

Agarwal, S.C. \& Stuart-Macadam, P. (2003): An evolutionary and biocultural approach to understanding the effects of reproductive factors on the female skeleton. - In: Agarwal, S.C. \& Stout, S. (eds): Bone loss and osteoporosis: an anthropological perspective. - Kluwer Academic/Plenum Publishers, New York, pp. 105-119.

Agarwal, S.C., Dumitriu, M., Tomlinson, G. \& Grynpas, M. (2004): Medieval trabecular bone architecture: the influence of age, sex, and lifestyle. - Am. J. Phys. Anthropol. 124: 33-44.

Agarwal, S.C. \& Grynpas, M.D. (2009): Measuring and interpreting age-related loss of vertebral bone mineral density in a Medieval population. - Am. J. Phys. Anthropol. 139: 244-252.

Allali, F., Maaroufi, H., El Aichaoui, S., Khazani, H., Saoud, B., Benyahya, B., Abouqal, R. \& Hajjaj-Hassouni, N. (2007): Influence of parity on bone mineral density and peripheral fracture risk in Moroccan postmenopausal women. - Maturitas 57: 392-398.

Alves, A.M.N. \& Almeida, M.D.V. (1992): Alimentação materna. Breve perspectiva histórica. - Rev. Port. Nutr. 4: 8-33.

Armelagos, G., Mielke, J., Owen, K., Van Gerven, D., Dewey, J. \& Mahler, P. (1972): Bone growth and development in prehistoric populations from Sudanese Nubia. - J. Hum. Evol. 1: 89-119.

Barata, O.S. (1985): Demografia e evolução social em Portugal. Anal. Soc. 21: 981-993.

Beauchesne, P. \& Agarwal, S.C., (2017): A multi-method assessment of bone maintenance and loss in an Imperial Roman population: Implications for future studies of age-related bone loss in the past. - Am. J. Phys. Anthropol. 164: 41-61.

Bergot, C., Wu, Y., Jolivet, E., Zhou, L., Laredo, J. \& Rousson, V. (2009): The degree and distribution of cortical bone mineralization in the human femoral shaft change with age and sex in a microradiographic study. - Bone 45: 435-442.

Bonnick, S. (2010): Bone densitometry in clinical practice Application and interpretation. - Humana Press, Totowa.

Brickley, M. \& Ives, R. (2008): The bioarchaeology of metabolic bone disease. - Academic Press, Oxford.

Cavkaytar, S., Seval, M.M., Atak, Z. Rahime, B., Findik, S. \& Ture, D. (2015): Effect of reproductive history, lactation, first pregnancy age and dietary habits on bone mineral density in natural postmenopausal women. - Aging Clin. Exp. Res. 27: 689-694.

Chamberlain, A.T. (2006): Demography in Archaeology. Cambridge University Press, Cambridge.

Cho, H. \& Stout, S.D. (2003): Bone remodelling and age-associated bone loss in the past: A histomorphometric analysis of the Imperial Roman skeletal population of Isola Sacra. - In: Agarwal, S.C. \& Stout, S.D. (eds): Bone loss and osteoporosis. An anthropological perspective. - Kluwer Academic/Plenum Publishers, New York, pp. 207-228.

Cohen, J. (1988): Statistical power analysis for the behavioral sciences. - Lawrence Earlbaum Associates, Hillsdale.

Cooke-Hubley, S., Kirby, B.J., Valcour, J.E., Mugford, G., Adachi, J.D. \& Kovacs, C.S. (2017): Spine bone mineral density increases after 6 months of exclusive lactation, even in women who keep breastfeeding. - Arch. Osteoporos. 12 (1): 73. doi: 10.1007/s11657-017-0368-6 
Crandall, C.J., Liu, J., Cauley, J., Newcomb, P.A., Manson, J.E., Vitolins, M.Z., Jacobson, L.T., Rykman, K.K. \& Stefanick, M.L. (2017): Associations of parity, breastfeeding, and fractures in the Women's Health Observational Study. - Obstet. Gynecol. 130: 171-180.

Cross, N.A., Hillman, L.S., Allen, S.H., Krause, G.F. \& Vieira, N.E. (1995): Calcium homeostasis and bone metabolism during pregnancy, lactation, and postweaning: a longitudinal study. - Am. J. Clin. Nutr. 61: 514-523.

Cunha, E., Baccino, E., Martrille, E., Rahmstaler, F., Prieto, J., Schuliar, Y., Lynnerup, N. \& Cattaneo, C. (2009): The problem of aging human remains and living individuals: A review. Forensic Sci. Int. 193: 1-13.

Cunha, E. \& Wasterlain, S. (2007): The Coimbra identified skeletal collections. - In: Grupe, G. \& Peters, J. (eds): Skeletal series and their socio-economic context. - Verlag Marie Leidorf GmbH, Rahden/Westf., pp. 23-33.

Curate, F. (2014a): Osteoporosis and paleopathology: A review. - J. Anthropol. Sci. 92: 119-146.

Curate, F. (2014b): Osteoporosis and nutrition - A paleopathological insight. - Antropol. Port. 30: 29-51.

Curate, F., Pedroso de Lima, J., Albuquerque, A., Ferreira, I., Correia, J. \& Cunha, E. (2012): Parto, morte e massa óssea na Colecção de Esqueletos Identificados do Museu Antropológico da Universidade de Coimbra (Portugal): alguns avanços preliminares. - Cad. GEEvH 1: 57-65.

Curate et al. (2013): no corresponding reference in reference list PLEASE INSERT MISSING REFERENCE HERE

Cure-Cure, C., Cure-Ramirez, P., Teran, E. \& Lopez-Jaramillo, P. (2002): Bone-mass peak in multiparity and reduced risk of bone fractures in menopause. - Int. J. Gynaecol. Obstet. 76: 285-291.

Dewey, J., Armelagos, G. \& Bartley, M. (1969): Femoral cortical involution in three Nubian archaeological populations. - Hum. Biol. 41: 13-28.

El Maghraoui, A., Guerboub, A.A., Achemlal, L., Mounach, A., Nouijai, A., Ghazi, M., Bezza, A. \& Tazi, M.A. (2006): Bone Mineral Density of the Spine and Femur in Healthy Moroccan Women. - J. Clin. Densitom. 9: 454-460.

Ekenman, I., Eriksson, S. \& Lindgren, J. (1995): Bone density in medieval skeletons. - Calcif. Tissue Int. 56: 355-358.

Ericksen, M.F. (1976): Cortical bone loss with age in three Native American populations. - Am. J. Phys. Anthropol. 45: 443-452.

Ferrari, S., Bianchi, M.L., Eisman, J.A., Foldes, A.J., Adami, S. \& Wahl, D.A. (2012): Osteoporosis in young adults: pathophysiology, diagnosis, and management. - Osteoporos. Int. 23: 2735-2748.

Haloi, A. \& Limbu, D. (2013): Nutritional status, fertility and factors associated with anaemia: A cross sectional study among a rural population of Muslim women in Assam, India. - Anthropol. Anz. 70: 193-201. doi: 10.1127/0003-5548/2013/0268

Head-König, A.-L., Lorenzetti, L. \& Veyrassat, B. (2001): Famille, parenté et réseaux en Occident (XVIIe-XXe siècles): Mélanges offerts à Alfred Perrenoud. - Société d'Histoire et d'Archéologie de Genève, Genève.

Henderson, C.Y. \& Padez, C. (2017): Testing times: identifying puberty in an identified skeletal sample. - Ann. Hum. Biol. 44: 332-337.

Henderson, P., Sowers, M., Kutzko, K. \& Jannausch, M. (2000): Bone mineral density in grand multiparous women with extended lactation. - Am. J. Obstet. Gynecol. 182: 1371-1377.
Holck, P. (2007): Bone mineral densities in the Prehistoric, VikingAge and Medieval populations of Norway. - Int. J. Osteoarchaeol. 17: 199-206.

Holmberg-Marttila, D., Sievanen, H. \& Tuimala, R. (1999): Changes in bone mineral density during pregnancy and postpartum: prospective data on five women. - Osteoporos. Int. 10: $41-46$.

Jang, D.G., Kwon, J.Y., Choi, S.K., Ko, H.S., Shin, J.C. \& Park, I.Y. (2016): Prevalence of low bone mineral density and associated risk factors in Korean puerperal women. - J. Korean Med. Sci. 31: 1790-1796.

Karlsson, M.K., Ahlborg, H.G. \& Karlsson, C. (2005): Maternity and bone mineral density. - Acta Orthop. 76: 2-13.

Kline, R.B. (2010): Principles and practice of structural equation modeling. - The Guildford Press, New York.

Kneissel, M., Boyde, A., Hahn, M., Teschler-Nicola, M., Kalchhauser, G. \& Plenk, H. (1997): Age- and sex-dependent cancellous bone changes in a $4000 \mathrm{y}$ BP population. - Bone 15 : 539-545.

Kojima, N., Douchi, T., Kosha, S. \& Nagata, Y. (2002): Crosssectional study of the effects of parturition and lactation on bone mineral density later in life. - Maturitas 41: 203-209.

Kolthoff, N., Eiken, P., Kristense, B. \& Nielsen, S.P. (1998): Bone mineral changes during pregnancy and lactation: a longitudinal cohort study. - Clin. Sci. 94: 405-412.

Kovacs, C.S. (2016): Maternal mineral and bone metabolism during pregnancy, lactation, and post-weaning recovery. - Physiol. Rev. 96: 449-547.

Kraemer, B., Schneider, S., Rothmund, R., Fehm, T., Wallwiener, D. \& Solomayer, E.F. (2012): Influence of pregnancy on bone density: a risk factor for osteoporosis? Measurements of the calcaneus by ultrasonometry. - Arch. Gynecol. Obstet. 285: 907-912.

Krishnakumar, R., Kumar, A.T. \& Kuzhimattam, M.J. (2016): Spinal compression fractures due to pregnancy-associated osteoporosis. - J. Craniovertebr. Junction Spine 7: 224-227.

Laskey, M.A. \& Prentice, A. (1999): Bone mineral changes during and after lactation. - Obstet. Gynecol. 94: 608-615.

Lees, B., Molleson, T., Arnett, T.R. \& Stevenson, J.C. (1993): Differences in proximal femur bone density over two centuries. - Lancet 341: 673-675.

Lems, W. \& Raterman, H. (2017): Critical issues and current challenges in osteoporosis and fracture prevention. An overview of unmet needs. - Ther. Adv. Musculoskel. Dis. 9: 299-316.

Levine, T.R. \& Hullett, C.R. (2002): Eta Squared, Partial Eta Squared, and misreporting of effect size in communication research. - Hum. Commun. Res. 28: 612-625.

Luna, F., Camargo, A.M., Alonso, V. \& Moral, P. (2014): Effects of parental reproductive behavior on offspring sex ratio in a preindustrial western Mediterranean population (La Alpujarra, 1900-1950, SE Spain). - Anthropol. Anz. 71: 303-312. doi: 10.1127/0003-5548/2014/0398

Madimenos, F.C., Snodgrass, J., Blackwell, A.B., Liebert, M.A., Cepon, T.J. \& Sugiyama, L.S. (2011): Normative calcaneal quantitative ultrasound data for the indigenous Shuar and nonShuar colonos of the Ecuadorian Amazon. - Arch. Osteopor. 6: 39-49.

Madimenos, F.C., Snodgrass, J., Liebert, M.A., Cepon, T.J. \& Sugiyama, L.S. (2012): Reproductive effects on skeletal health in Shuar women of Amazonian Ecuador: A life history perspective. - Am. J. Hum. Biol. 24: 841-852. 
Martin, D. \& Armelagos, G.J. (1979): Morphometrics of compact bone: an example from Sudanese Nubia. - Am. J. Phys. Anthropol. 51: 571-577.

Martin, D., Armelagos, G., Goodman, A. \& Van Gerven, D. (1984): The effects of socioeconomic change in prehistoric Africa: Sudanese Nubia as a case study. - In: Cohen, M. \& Armelagos, G. (eds): Paleopathology at the origins of agriculture. Academic Press, Orlando, pp. 193-214.

Martin, D., Goodman, A. \& Armelagos, G. (1985): Skeletal pathologies as indicators of quality and quantity of diet. - In: Gilbert, R. \& Mielke, J. (eds): The analysis of prehistoric diets. Academic Press, New York, pp. 227-279.

Mays, S.A. (2000): Age-dependent cortical bone loss in women from $18^{\text {th }}$ and early $19^{\text {th }}$ century London. - Am. J. Phys. Anthropol. 112: 349-361.

Mays, S.A. (2010): The effects of infant feeding practices on infant and maternal health in a medieval community. - Child. Past. 3: 63-78.

Mays, S.A., Lees, B. \& Stevenson, J.C. (1998): Age-dependent bone loss in the femur in a medieval population. - Int. J. Osteoarchaeol. 8: 97-106.

Mays, S.A., Turner-Walker, G. \& Syversen, U. (2006): Osteoporosis in a population from medieval Norway. -Am. J. Phys. Anthropol. 131: 343-351.

Møller, U.K., Streym, S., Mosekilde, L. \& Rejnmark, L. (2012): Changes in bone mineral density and body composition during pregnancy and postpartum. A controlled cohort study. Osteoporos. Int. 23: 1213-1223.

Morais, M.G. (1983): A substituição das gerações em Portugal: análise regional (1930-75). - Anal. Soc. 19: 79-99.

Mulhern, D. \& Van Gerven, D. (1997): Patterns of femoral bone remodeling dynamics in a Medieval Nubian population. - Am. J. Phys. Anthropol. 104: 133-146.

Namgung, R. \& Tsang, R. (2003): Bone in the pregnant mother and newborn at birth. - Clin. Chim. Acta 333: 1-11.

Nazareth, J.M. (1978): A dinâmica da população portuguesa no período 1930-70. - Anal. Soc. 14: 729-800.

Nguyen, H.T.T., von Schoultz, B., Pham, D.M.T., Nguyen, D.B., Le, Q.H., Nguyen, D.V., Hirschberg, A.L. \& Nguyen, T.V. (2009): Peak bone mineral density in Vietnamese women. Arch. Osteoporos. 4: 9-15.

Pearce, K.L. (2006): Breastfeeding and bone density change. - PhD Thesis, University of Massachussets, Amherst.

Peck \& Stout (2007): no corresponding reference in reference list PLEASE INSERT MISSING REFERENCE HERE

Pfeiffer, S.K. \& Lazenby, R.A. (1994): Low bone mass in past and present Aboriginal populations. - In: Draper, H. (ed.): Advances in Nutritional Research: Nutrition and osteoporosis. - Plenum Press, New York, pp. 35-51.

Piperata, B.A. (2009): Variation in maternal strategies during lactation: the role of the biosocial context. - Am. J. Hum. Biol. 21: $817-827$.

Plochocki 2009: no corresponding reference in reference list PLEASE INSERT MISSING REFERENCE HERE

Poulsen, L., Qvesel, D., Brixen, K., Vesterby, A. \& Boldsen, J. (2001): Low bone mineral density in the femoral neck of medieval women: a result of multiparity? - Bone 28: 454-458.

Prentice, A. (2000): Calcium in pregnancy and lactation. - Annu. Rev. Nutr. 20: 249-272.
Ritchie, L.D., Fung, E.B., Halloran, B.P., Turnlund, J.R., Van Loan, M.D., Cann, C.E. \& King, J.C. (1998): A longitudinal study of calcium homeostasis during human pregnancy and lactation and after resumption of menses. - Am. J. Clin. Nutr. 67: 693-701.

Sioka, C., Fotopoulos, A., Georgiou, A., Xourgia, X., Papadopoulos, A. \& Kalef-Ezra, J.A. (2010): Age at menarche, age at menopause and duration of fertility as risk factors for osteoporosis. Climacteric 13: 63-71.

Sperling, S. \& Beyene, Y. (1997): A pound of Biology and a pinch of Culture or a pinch of Biology and a pound of Culture? The necessity of integrating Biology and Culture in reproductive studies. - In: Hager, L. (ed.): Women in Evolution. - Routledge, New York, pp. 137-152.

Streeten, E.A., Ryan, K.A., McBride, D.J., Pollin, T.I., Shuldiner, A.R. \& Mitchell, B.D. (2005): The relationship between parity and bone mineral density in women characterized by a homogeneous lifestyle and high parity. - J. Clin. Endocrinol. Metab. 90: 4536-4541.

To, W.W. \& Wong, M.W. (2012): Bone mineral density during pregnancy in actively exercising women as measured by quantitative ultrasound. - Arch. Gynecol. Obstet. 286: 357-363.

Turner-Walker, G., Syversen, U. \& Mays, S. (2001): The archaeology of osteoporosis. - Eur. J. Archaeol. 4: 263-269.

Ulijaszek, S. \& Kerr, D. (1999): Anthropometric measurement error and the assessment of nutritional status. - Brit. J. Nutr. 82: $165-177$.

Ulrich, U., Miller, P., Eyre, D., Chesnut, C., Schlebusch, H. \& Soules, M. (2003): Bone remodeling and bone mineral density during pregnancy. - Arch. Gynecol. Obstet. 268: 309-316.

Vogel, M., Hahn, M., Caselitz, P., Woggan, J., Pompesius-Kempa, M. \& Delling, G. (1990): Comparison of trabecular bone structure in man today and an ancient population in Western Germany. - In: Takahashi, H.E. (ed.): Bone morphometry. Nishimura Co., Tokyo, Japan, pp. 220-223.

Wei, W., Shary, J.R., Garrett-Mayer, E., Anderson, B., Forestieri, N., Hollis, B. \& Wagner, C. (2017): Bone mineral density during pregnancy in women participating in a randomized controlled trial of vitamin D supplementation. - Am. J. Clin. Nutr. 106: 1422-1430. doi: 10.3945/ajen.116.140459.

White, C. \& Armelagos, G. (1997): Osteoporosis and isotopes in X-group Nubians. - Am. J. Phys. Anthropol. 103: 185-200.

Willis, A. \& Oxenham, M. (2013): A case of maternal and perinatal death in Neolithic Southern Vietnam, c. 2100-1050 BCE. - Int. J. Osteoarchaeol. 23: 676-684.

World Health Organization (1994): International classification of diseases and related health problems. $10^{\text {th }}$ revision. - WHO, Geneva.

Zhang, H., Sol-Church, K., Rydbeck, H., Stabley, D., Spotila, L.D. $\&$ Devoto, M. (2009): High resolution linkage and linkage disequilibrium analyses of chromosome 1p36 SNPs identify new positional candidate genes for low bone mineral density. Osteoporos. Int. 20: 341-346.

Manuscript received: 11 January 2018

Revisions required: 25 February 2018

Revised version received: 05 April 2018

Accepted: 05 April 2018 